\title{
EL CAMBIO CLIMÁTICO: LOS ASPECTOS CIENTÍFICOS Y ECONÓMICOS MÁS RELEVANTES
}

\author{
Cristina García Fernández \\ Universidad Complutense de Madrid
}

\begin{abstract}
Resumen: El calentamiento global se ha convertido, en los últimos años, en uno de los temas científicos, políticos y económicos más relevantes. Según el IPCC (Panel Intergubernamental de Cambio Climático), el período comprendido entre 1995 y 2006 parece haber sido uno de los más cálidos registrados hasta ahora desde 1850. Variables relevantes tales como las alteraciones en la temperatura oceánica, cambios en los ecosistemas terrestres (como la disminución de la extensión de la capa de nieve y hielo en el hemisferio norte), el acortamiento de las estaciones frías, el derretimiento de glaciares, la disminución de la extensión del permafrost y el aumento del nivel del mar, proporcionan una evidencia clara de que el mundo se está calentando. Ralentizar y limitar el cambio climático requiere, a largo plazo, un gran esfuerzo a nivel internacional. La vía actual más importante la constituye el Convenio de Naciones Unidas para el Cambio Climático, el cual ha sido ratificado por 189 países. Pero también es importante tomar medidas preventivas a nivel nacional. Los países industrializados han hecho algún progreso, aunque limitado, en frenar las emisiones de GHG (gases de efecto invernadero) desde 1990. Durante este período se ha reconocido la necesidad urgente de diseñar políticas específicas, como la utilización de permisos de emisiones, impuestos sobre la energía y medioambientales, medidas voluntarias del sector industrial, políticas de regulación y una creciente investigación y creación de programas destinados a la mitigación. Este artículo pretende presentar, de forma sintética, la realidad actual, tanto científica como económica, del cambio climático, las políticas económicas más eficientes que pueden prevenirlo o ralentizarlo y la importancia de los costes que de éstas se derivan. El riesgo de que el cambio climático endurezca los impactos hace que sea urgente el compromiso de tomar medidas significativas encaminadas a reducir las emisiones de GHG durante las próximas décadas. La política económica y la política medioambiental deben actuar conjuntamente en la consecución de este objetivo.
\end{abstract}

Palabras clave: cambio climático, políticas económicas preventivas, calentamiento global.

\section{Climate Change: The Most Relevant Scientific and Economic Aspects}

Abstract: During the last years, global warming has turned into one of the most important scientific, political and economic items. The IPCC (Intergovernmental Panel on Climate Change) affirms that the period between 1995 and 2006 has been one of the warmest since 1850 . Climate change is already being observed through rising temperatures, melting glaciers, shifting rain patterns, increased storm intensity and rising sea levels. These factors are the evidence that the world is getting warmer. To slow and limit climate change requires, in the long run, a great international effort. The United Nations Frame on Climate Change has been ratified by 189 countries. But it is also important to implement preventive national measures. Since 1990, industrialized countries, although limited, have made some progress in cutting GHG (greenhouse gases) emissions. During this time the countries have urged the implementation of specific policies, like the use of emission permits, energy and environmental taxes, industrial voluntary measures, regulatory policies and an increasing researching programs related to mitigation. This paper aims to present, in a synthetic way, the scientific and economic actual state of the climate change problem and the alternatives to reduce global warming together with the economic costs. The risk of serious climate change impacts suggests that urgent action is needed to significantly reduce GHG emissions in the coming decades. Political economy and environmental economy must work together in order to fulfil this objective.

Keywords: climate change policies; cost of reducing carbon emissions

JEL classification: $\mathrm{H} 41, \mathrm{Q} 51, \mathrm{Q} 54$. 


\section{INTRODUCCIÓN}

Este documento tiene un doble cometido: ofrecer las información más concluyente sobre los aspectos científicos del cambio climático y orientar sobre cuáles son los instrumentos de política económica más adecuados para solventar, o la menos ralentizar, el efecto invernadero y el calentamiento global subsiguiente.

Gran parte de la investigación llevada a cabo hasta la fecha sobre el cambio climático ha sido realizada por los climatólogos. Su cometido principal ha sido estimar el grado de calentamiento actual, así como el período de tiempo que transcurre hasta que éste se transforma en temperaturas globales más elevadas. Para ello, elaboran predicciones sobre la demanda de energía futura. Basándose en estas predicciones determinan el tipo y la cantidad de combustibles fósiles que serán requeridos para satisfacer dicha demanda. Una vez hecho esto, la cantidad de gases invernadero puede ser calculada a partir de las propiedades físicas de los respectivos combustibles. Finalmente, y por medio de los Modelos de Circulación General del Clima (GCMs), los climatólogos calculan los cambios climáticos esperados en todo el mundo.

Los economistas, por otra parte, han concentrado su estudio en los costes de reducir las emisiones de dióxido de carbono (CO2). Utilizan una combinación de instrumentos de política económica para reducir las emisiones hasta niveles determinados y observan los efectos que producen estos instrumentos sobre la actividad económica. Es decir, si los climatólogos estiman necesaria una reducción del $20 \%$ en las emisiones de $\mathrm{CO} 2$, entonces los economistas especifican de manera exógena el nivel de esta reducción en sus modelos y determinan las actuaciones que son necesarias para llevarla a cabo. Con esta metodología pueden incluso especificar las pérdidas o ganancias económicas que produce la aplicación de esas medidas -por ejemplo, los efectos de los impuestos sobre el carbono-. No obstante, esta metodología suele ignorar los beneficios que reporta una reducción de las emisiones de $\mathrm{CO} 2$, ya que los costes pueden calcularse de manera relativamente inmediata, mientras que los beneficios sólo se observan en el futuro.

Debido a que el cometido de este trabajo es muy ambicioso, ya que abarcamos gran parte la problemática sobre el calentamiento global, el contenido de cada apartado será breve, otorgando la información más relevante en cada caso. Dicha información se podrá ampliar haciendo uso de las referencias que en todo momento guían este documento. 


\section{LA ACTIVIDAD HUMANA COMO FUENTE DEL CAMBIO CLIMÁTICO}

La variación de las concentraciones de gases de efecto invernadero y aerosoles en la atmósfera, y las variaciones de la cubierta terrestre y de la radiación solar, alteran el equilibrio energético del sistema climático. Durante las últimas décadas existe evidencia de que son las actividades humanas (quema de combustibles fósiles, actividades agrarias, etc) las que están impulsando las concentraciones atmosféricas de gases invernadero (Gl) produciendo un efecto de calentamiento sobre la superficie terrestre. Los científicos llevan tiempo mostrando que las mayores concentraciones de Gl están alterando el clima regional y global, a través de la alteración de parámetros relacionados directamente con este: temperatura, precipitaciones, humedad, suelo y nivel del mar. Los estudios más recientes muestran que el cambio climático (CC) tendrá cada vez mayor impacto sobre los ecosistemas naturales y socioeconómicos: cuanto más rápidamente cambie el clima, mayores serán los riesgos para nuestro planeta.

Según el IPCC (Panel Intergubernamental de Cambio Climático), las emisiones mundiales de Gl por efecto de actividades humanas han aumentado, desde la era preindustrial, en un 70\% entre 1970 y 2004. El dióxido de carbono (CO2), aunque menos nocivo que otros, es el Gl antropogénico más importante, porque es el que más se emite. Sus emisiones anuales aumentaron en torno a un $80 \%$ entre 1970 y 2004, (IPCC, 2007).

Las concentraciones atmosféricas mundiales de $\mathrm{CO} 2$, metano $(\mathrm{CH} 4)$ y óxido nitroso (N2O) han aumentado notablemente por efecto de las actividades humanas desde 1750, y son actualmente muy superiores a los valores preindustriales. Las concentraciones atmosféricas de $\mathrm{CO} 2(379 \mathrm{ppm})$ y $\mathrm{CH} 4$ (1774 ppm) exceden con mucho el intervalo natural de valores de los últimos 650.000 años.

Los aumentos de la concentración mundial de $\mathrm{CO} 2$ se deben principalmente a la utilización de combustibles de origen fósil y, en una parte apreciable pero menor, a los cambios de uso de la tierra. El aumento observado de la concentración de metano se debe predominantemente a la agricultura y a la utilización de combustibles de origen fósil. El aumento de metano ha sido menos rápido desde comienzos de los años 90 , en concordancia con las emisiones totales (como suma de fuentes antropogenias y naturales), que han sido casi constantes durante ese período. El aumento de la concentración de $\mathrm{N} 2 \mathrm{O}$ procede principalmente de la agricultura. El efecto neto de las actividades humanas desde 1750 ha sido un aumento de la temperatura.

La estabilización de las concentraciones demandará un gran esfuerzo, exigiendo serias mejoras de eficiencia energética y cambios drásticos en los sistemas económicos. 


\section{Cuadro 1}

Las actividades humanas producen el cambio climático

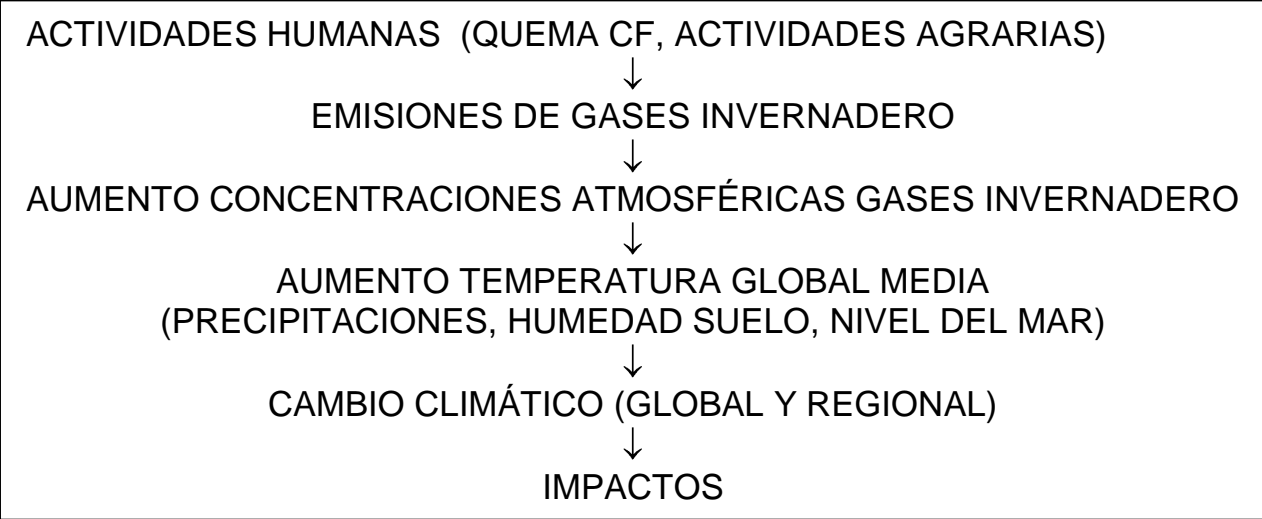

El cuadro anterior resume lo que es el proceso completo del fenómeno del cambio climático. Todo comienza con las actividades humanas que expulsan a la atmósfera Gl. Estas se transforman en concentraciones que difícilmente pueden ser eliminadas y que provocan aumentos de la temperatura global media. Dichos incrementos de la temperatura alteran los distintos parámetros relacionados con el clima (precipitaciones, etc) lo que, finalmente, da lugar al cambio climático a nivel global y regional.

\section{LA ACTUALIDAD CIENTÍFICA SOBRE EL CAMBIO CLIMÁTICO}

El Grupo Intergubernamental de Expertos sobre el Cambio Climático, en su último informe de evaluación, determinó que "el calentamiento del sistema climático es innegable" y que la mayor parte del incremento registrado se debe "al incremento observado en las concentraciones de gases de efecto invernadero de origen antropogénico" (IPCC, 2007a). Esto ha provocado incrementos en la temperatura del aire (aproximadamente, $0,7^{\circ} \mathrm{C}$ ) durante los últimos 100 años, así como de las aguas, con el consecuente aumento del nivel del mar de entre $2,4 \mathrm{~mm}$ y $3,8 \mathrm{~mm}$ por año (entre 1993 y 2003).

En el año 2000, el IPCC desarrolló seis escenarios posibles para medir el efecto del cambio climático en el futuro, que variaban según el grado de compromiso y cumplimiento en la reducción de las emisiones de Gl. El peor de los escenarios, que consiste en no hacer mucho para evitarlo ("bussiness as usual"), sugiere un incremento de la temperatura para fin de siglo de $6,4{ }^{\circ} \mathrm{C}$ (IPCC, 2007a). Estos escenarios potenciales han despertado un consenso generalizado entre los Estados de que el aumento de la temperatura global no debería superar los $2{ }^{\circ} \mathrm{C}$, ya que por encima de este tope la "respuesta climática" (cambios secundarios debido al ascenso de la temperatura) y otros eventos "se tornarían impredecibles y el planeta podría llegar a un punto de inflexión, más allá del cual los efectos del cambio climático no podrían ser revertidos".

Parece haber acuerdo entre los expertos en cuanto a que si la temperatura aumenta más de $2^{\circ} \mathrm{C}$, el nivel del mar continuará elevándose, la acidificación 
de los océanos y el repliegue del hielo marino aumentarán, las precipitaciones se incrementarán en las zonas de latitud alta y disminuirán en las regiones subtropicales, y es "muy probable que cada vez sean más frecuentes las condiciones extremas, las olas de calor y las fuertes precipitaciones" (IPCC, 2007). Ya es posible advertir el impacto en los sistemas biológicos, como el desborde de lagos glaciares, el acortamiento de los ciclos de crecimiento, la pérdida de los humedales costeros y la decoloración de los corales marítimos. Si el aumento de la temperatura supera los 1,5 ó $2,5^{\circ} \mathrm{C}$, es posible que entre el 20 y el 30 por ciento de las especies de plantas y animales se expongan a un mayor riesgo de extinción.

Es difícil predecir cuál será el impacto de todo esto para el desarrollo humano, si bien el IPCC ha concluido que es muy probable que todas las regiones sufran efectos económicos negativos, pero especialmente "se espera que los países en desarrollo experimenten las mayores pérdidas porcentuales" (IPCC, 2007b). Las sociedades más vulnerables serán aquellas cuyas economías estén estrechamente vinculadas a recursos sensibles a los aspectos del clima y en zonas de rápida urbanización, donde el crecimiento de la población ya impone fuertes exigencias a recursos limitados.

\section{Cuadro 2 \\ Evolución de las emisiones de GI}

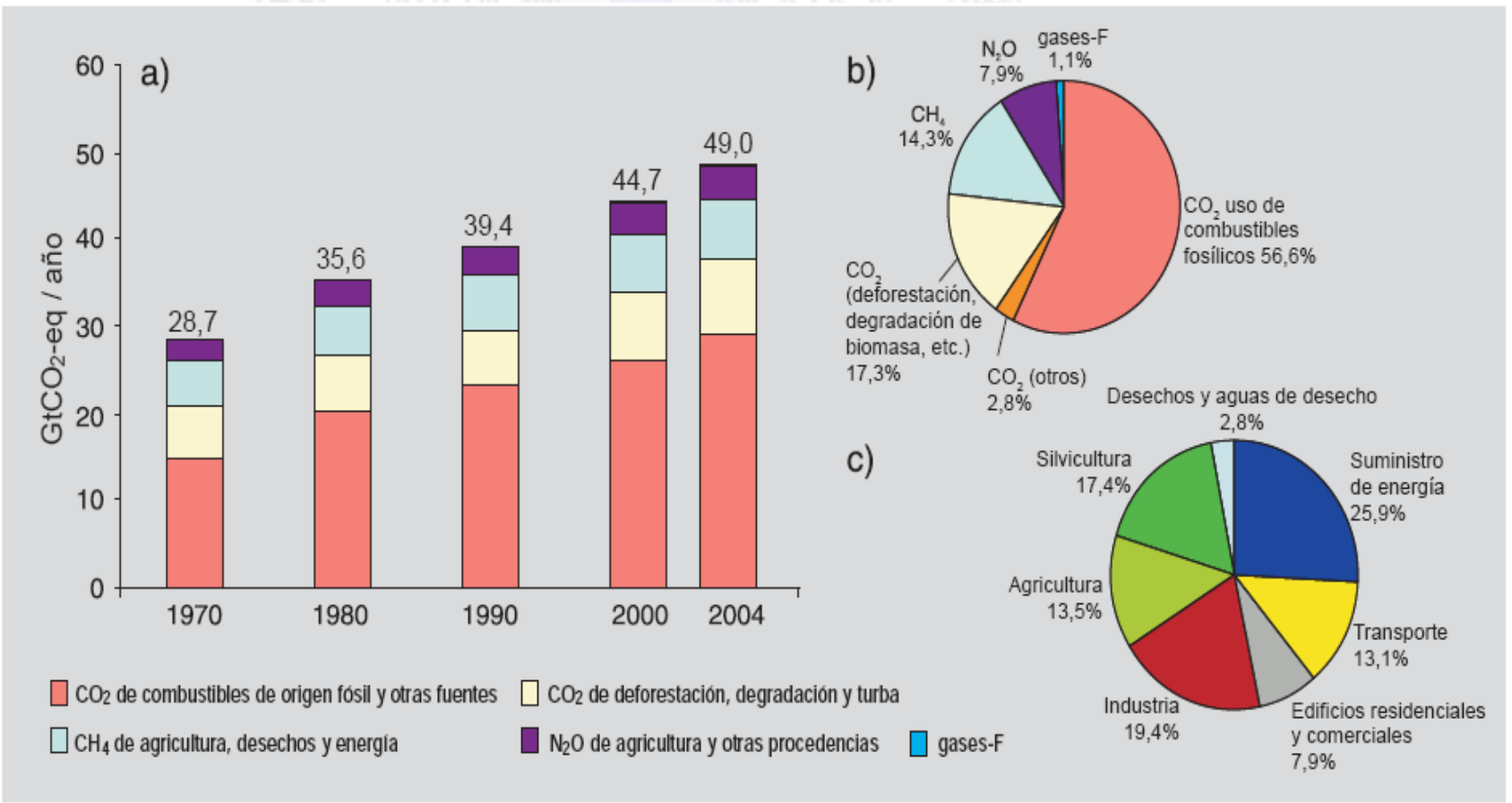

Fuente: IPCC, 2007.

El cuadro 2 muestra las emisiones de GI (en C02 equivalente) para distintos años. También indica la procedencia de las emisiones por sectores 
económicos. Claramente, es el C02 procedente del uso de los combustibles fósiles el gas invernadero que más se expulsa a la atmósfera, siendo su emisión creciente.

En el Acuerdo de Copenhague de 2009 y en el de Cancún de 2010, en este último de forma oficial aprobado por Naciones Unidas (Acuerdos de Cancún ${ }^{1}$ ), la comunidad internacional adoptó el objetivo y ya compromiso de que el calentamiento global no debe superar los $2^{\circ} \mathrm{C}$ sobre el nivel preindustrial (Grubb, 2010). En consecuencia con tal objetivo, las emisiones de Gl deberían alcanzar su valor máximo en 2020 como mucho, y deberían ser reducidas al menos a un 50\% (con respecto al año base de 1990) en el año 2050. Los países desarrollados, como grupo, deberían reducir sus emisiones entre el 25 y el $40 \%$ (con respecto a 1990) en el año 2020 y entre el 80 y el 95\% en 2050 (con respecto a 1990). Se trata de un objetivo de temperatura muy ambicioso para todos los países del mundo, puesto que alcanzarlo implica transformaciones radicales de las estructuras económicas y energéticas.

La Comisión Europea ha publicado recientemente (marzo de 2011) una comunicació $^{2}$ donde se analiza la transición hacia una economía con baja intensidad en carbono (Comisión Europea, 2011). Una de las iniciativas que se apuntan en esta comunicación es la utilización eficiente de los recursos. Para ello se establecen dos objetivos. El primero consistiría en desligar el crecimiento económico del mayor uso de los recursos y, el segundo, procurar el cambio hacia una economía con bajas emisiones de carbono, propiciando un mayor uso de las energías renovables, modernizando el sistema de transporte y promoviendo la eficiencia energética.

Son ya numerosos los países y regiones que han puesto en marcha políticas reductoras de emisiones. La propia UE, California, e incluso China se cuentan entre aquéllos con políticas más ambiciosas. Si bien el Convenio Marco de las Naciones Unidas sobre el Cambio Climático y el Protocolo de Kyoto constituyen la base de la cooperación internacional, es necesaria ya la adopción de medidas inmediatas en todo el mundo.

\section{CAMBIO CLIMATICO, EFECTO INVERNADERO Y FORZAMIENTO RADIATIVO}

Dada la confusión que suele haber sobre estos fenómenos, conviene hacer una breve referencia a ellos, al menos, a nivel conceptual.

El Convenio Marco de las NU sobre Cambio Climático define el Sistema Climático como la totalidad de la atmósfera, hidrosfera, biosfera, geosfera y sus interacciones. Otros conceptos relevantes son los siguientes: 


\section{Cambio climático}

Un cambio en el clima que es atribuido directa o indirectamente a la actividad humana que altera la composición de la atmósfera global y que se suma a la variabilidad observada a lo largo de períodos de tiempo comparables. Por lo general, cambio climático hace referencia a las interferencias humanas, mientras que variabilidad climática se refiere a los cambios naturales.

\section{Gases Invernadero}

Aquellos componentes gaseosos de la atmósfera, tanto naturales como antropogénicos, que absorben y reemiten radiación infrarroja. Hablamos del vapor agua, dióxido carbono, oxido nitroso, metano y clorofluorocarbonos (CFCs).

\section{Efecto Invernadero natural}

La fuente energética elemental que influye en el clima es la radiación solar (radiación de onda corta). Alrededor de un tercio de la radiación solar entrante es reflejada de nuevo al espacio, en particular por las nubes. El resto es absorbido por la atmósfera, tierra, océano y superficies heladas. La Tierra y la atmósfera emiten radiación que sale en forma de ondas largas infrarrojas. Una parte de esa radiación saliente queda atrapada por los Gl producidos de forma natural (vapor agua, dióxido de carbono, ozono, metano y óxido nitroso) y por las nubes. Esa intervención de los Gl mantiene la superficie terrestre más caliente de lo que, de otro modo, hubiera estado (García, 1999).

\section{Forzamiento Radiativo}

Ocurre cuando se produce una variación de la radiación neta media (en la parte alta de la troposfera) originada por un cambio en la radiación solar o en la infrarroja. El forzamiento radiativo perturba el equilibrio entre la radiación entrante y saliente. El clima debe responder a la perturbación para restablecer el equilibrio radiativo, aumentando así la temperatura terrestre (si es positivo) ${ }^{3}$. Ejemplo: ante una duplicación del $\mathrm{CO} 2$, la temperatura de la superficie debería aumentar $1^{\circ} \mathrm{C}$ para mantener el equilibrio (sin tener en cuenta las realimentaciones); si tenemos en cuenta a estas últimas, entonces la temperatura debería aumentar entre 1,5 y $4,5^{\circ} \mathrm{C}$.

El forzamiento también puede ser negativo. Por ejemplo, los aerosoles producidos por la actividad humana reflejan la luz solar influyendo también en la formación de las nubes y haciéndolas más reflectivas. La actividad volcánica también aumenta la concentración de aerosoles en la estratosfera produciendo un forzamiento negativo.

3 Forzamiento radiativo positivo: sería un cambio en la radiación solar entrante o en la saliente: un aumento de la concentración $\mathrm{CO} 2$ atmosférico produce una reducción de la radiación infrarroja saliente, calentando la superficie terrestre. Esa reducción de la radiación infrarroja saliente debe tener una compensación para que se restablezca el equilibrio o balance energético: la temperatura de la superficie y de la troposfera debe subir, produciendo así un aumento de la radiación saliente. 
En definitiva, la magnitud y duración del CC debido a las actividades humanas dependerá de la concentración de Gl y de aerosoles, de sus tasas de crecimiento y de la respuesta que tenga el sistema climático (no se ha calculado de momento un forzamiento radiativo antropogénico neto).

\section{FACTORES MODERADORES}

Son aquellos que disminuyen la magnitud del calentamiento:

1. Sumideros de $\mathrm{CO} 2$

2. Azufre gaseoso

3. Erupciones volcánicas

4. reducción del ozono estratosférico

5. Descenso de la actividad solar

1. Los sumideros de $\mathrm{CO} 2$ son los siguientes: atmósfera, océano y sumideros terrestres. Estos últimos absorben alrededor de 1,4 gigatoneladas (GtC) de carbono.

La atmósfera y océano absorben la mitad de las emisiones de CO2 procedentes de la quema de combustibles fósiles (CF) y la deforestación. El aumento del $\mathrm{CO} 2$ en la atmósfera actúa como fertilizante, esto es, podría aumentar el crecimiento de plantas y provocar la revegetación de la Tierra. No obstante, parte del CO2 atmosférico es extraído de la atmósfera por procesos geológicos, biológicos e hidrológicos.

El océano es el mayor depósito de $\mathrm{CO} 2$ (almacena 60 veces mas carbono que la atmósfera). La capa mixta del océano contiene tanto carbono como la atmósfera (en los $75 \mathrm{~m}$ superiores). La zona abisal (la más profunda) contiene la mayor parte del carbono. Pero el CO2 se traslada desde la atmósfera hasta la zona abisal de forma muy lenta, casi constante. Sin la actividad del hombre, la atmósfera y el océano estarían en equilibrio. El carbono sobrante sería absorbido por el océano.

La biota de la superficie y el humus del suelo contienen 40 veces mas carbono que toda la atmósfera. Llamamos sumideros terrestres a la absorción de dióxido de carbono por la reforestación del Hemisferio Norte, al efecto fertilizador que produce el CO2 y a la fertilización del nitrógeno.

Queda todavía mucha incertidumbre en cuanto a la cuantificación de los procesos que contribuyen a la formación de sumideros. En los últimos años ha mejorado el conocimiento sobre el ciclo del carbono (principales fuentes antropogénicas de $\mathrm{CO} 2$ y sumideros). Por ejemplo, en cuanto a los sumideros se han detectado dos recientemente: la fertilización del CO2 y la del nitrógeno.

El efecto fertilizador del $\mathrm{CO} 2$ hace de sumidero porque el aumento del $\mathrm{CO} 2$ atmosférico puede estimular la fotosíntesis de árboles y plantas. Los estudios experimentales realizados a pequeña escala muestran que ese impulso 
fotosintético puede llegar a ser entre el $20-40 \%$ cuando se duplica el CO2 (bajo condición óptimas de agua y nutrientes).

El nitrógeno antropogénico puede actuar como un fertilizante. No obstante, los niveles altos de nitrógeno están frecuentemente asociados con acidificación y altas concentraciones de ozono en la superficie, lo que, a largo plazo, puede dañar los ecosistemas y reducir el almacenamiento de carbono.

2. Otro efecto moderador de la temperatura lo constituye el azufre gaseoso. Es un factor moderador ya que las emisiones de azufre pueden aumentar la concentración de partículas sobre las que se forman las nubes, haciendo que sean más blancas y reflectantes (albedo), dando lugar a disminución temperaturas globales.

3. Moderadores son también las erupciones volcánicas, ya que los aerosoles reflejan la luz solar, enfriando la temperatura.

4. La reducción del ozono estratosférico enfría la superficie terrestre porque el proceso de destrucción de la capa de ozono utiliza parte de la radiación entrante de onda corta.

Hay que tener en cuenta que el clima está cambiando continuamente. Durante el último período interglaciar (hace 125.000 años) el clima era mucho más cálido y el nivel del mar unos 6 metros más alto por la fundición de los casquetes polares. La diferencia con el fenómeno actual es que los cambios eran lentos y las especies se adaptaban (Erickson, 1992).

\section{FACTORES DE AMPLIFICACIÓN DEL CALENTAMIENTO (REALIMENTACIONES)}

Existen otros factores o fenómenos que lejos de moderar la temperatura terrestre la amplifican. Estos son los factores o efectos de realimentación.

1. Realimentación del vapor de agua: el aumento de la temperatura aumenta la tasa de acumulación de vapor de agua en la atmósfera. Debido a la importancia de este gas, su acumulación en la atmósfera potencia el Efecto Invernadero (EI), ya que reduce el flujo infrarrojo o calor que sale de la superficie.

2. Realimentación de nieve y hielo: el calentamiento global produce una "amplificación polar del calentamiento" que tiende a reducir la cubierta de nieve y hielo polar y, por tanto, aumenta la temperatura (aunque últimamente los modelos indican una reducida amplificación polar debido a cambios en la circulación del océano; este puede retrasar el calentamiento debido a su gran absorción de calor). Por otra parte, mayores precipitaciones debido al calentamiento pueden aumentar la cantidad de nieve o hielo y reducir este tipo de realimentación positiva (Clarke et al, 1996).

3. Realimentación del océano : este absorbe y almacena $\mathrm{CO} 2$; la tasa a que 
ese CO2 es liberado depende de la estructura térmica de los océanos. El calentamiento tiende a acelerar la liberación de CO2 a la atmósfera lo que aumenta el El. Pero el calentamiento global dependerá en gran medida de la forma en la que el océano responda a los cambios en la temperatura.

4. Realimentación de las nubes: efecto complicado ya que existen distintos tipos de nubes con propiedades diferentes. El calentamiento global aumenta la tasa de evaporación lo que hace que se formen más nubes. Una mayor cubierta da lugar a dos efectos:

- Nubes altas (realimentación positiva): atrapan la radiación solar que sale hacia el espacio. Calienta el sistema climático en 31 Wm2 (watios por metro cuadrado).

- Nubes bajas (realimentación negativa): efecto albedo: reflejan la energía solar entrante. Efecto enfriamiento de $48 \mathrm{Wm} 2$. Una mayor contaminación puede aumentar la cantidad de nubes bajas.

- Efecto global: hoy en día incierto, bajo investigación, pero los datos existentes muestran el predominio del efecto enfriamiento: un enfriamiento neto de $-17 \mathrm{Wm} 2$. La magnitud de estos efectos dependen de la cantidad, altitud y contenido de agua en las nubes.

\section{EVIDENCIA DEL CALENTAMIENTO GLOBAL}

Hace ya mucho tiempo que hay un consenso dentro de la comunidad científica acerca de que el cambio climático es algo evidente. En realidad, los científicos conocen los mecanismos del Efecto Invernadero desde 1896. El químico sueco Suante Arrhenius predijo entonces los efectos del $\mathrm{CO} 2$ sobre el clima y concluyó que las épocas glaciares previas tuvieron lugar, en parte, por la disminución del $\mathrm{CO} 2$ atmosférico. También calculó que una duplicación de la concentración de $\mathrm{CO} 2$ daría lugar a un calentamiento mundial de $5^{\circ} \mathrm{C}$. Con el fin de clarificar esta evidencia climática de origen antropogénico hemos considerado dos vertientes, la teórica, basada en la modelización del clima, y, la empírica, relacionada con los registros de climas pasados.

\section{Los registros de climas pasados (evidencia empírica).}

Climas pasados han ido dejando constancia en el hielo y en los sedimentos oceánicos (son las mejores evidencias). Tanto el hielo que está debajo de la superficie helada de la Antártida y Groenlandia (2 km de profundidad) como los sedimentos oceánicos almacenados, otorgan información sobre el clima de hace miles de años. Estas muestras evidencian que las temperaturas han ido cambiando junto a la concentración de Gl durante los últimos 100.000 años (Erickson, 1992). En concreto, las muestras de burbujas de aire extraídas del hielo a profundidades de 2000 metros ofrecen datos sobre niveles preindustriales de CO2. Los sedimentos oceánicos ofrecen una medida de la temperatura atmosférica en el tiempo que se formaron los depósitos (estos contienen $\mathrm{CO} 2, \mathrm{CH} 4, \mathrm{~N} 2 \mathrm{O}$ ). El estudio de las burbujas de aire atrapadas en el 
hielo como los sedimentos del océano muestra que existe correlación entre concentración atmosférica y temperatura, esto significa que en las épocas en las que se ha encontrado mayor concentración de Gl atrapada en dichas profundidades, la temperatura también se ha mostrado más alta.

\section{Modelización del clima (evidencia teórica)}

Para predecir el cambio climático se modeliza el clima a través de ordenadores potentes. Los modelos deben tener las características físicas y químicas del sistema climático (suelo, océanos, atmósfera, etc.). Los modelos más modernos incluyen los efectos de realimentación y los sumideros más importantes. Los modelos más importantes por su alcance en las predicciones son los siguientes:

\section{- Modelos del ciclo del carbono}

Muestran el paso de emisiones de carbono a concentraciones. Elaboran distintos escenarios que indican las implicaciones futuras de las concentraciones atmosféricas de $\mathrm{CO} 2$. Los modelos concluyen que únicamente podría mantenerse un nivel estable de concentración de $\mathrm{CO} 2$ si las emisiones antropogénicas cayeran por debajo de las de 1990.

\section{- M. de Circulación General (GCM)}

Muestran el paso de concentraciones atmosféricas de carbono a aumentos de la temperatura media global. Esto es la sensibilidad del clima ${ }^{4}$. Entre estos últimos, los más importantes son los modelos óceano-atmosféricos acoplados (William, et al, 2005) y (Ruiz de Elvira, 1991). Estos informan de cómo el sistema climático responde a los cambios de la composición química de la atmósfera.

En general, la modelización consiste en duplicar las concentraciones atmosféricas de $\mathrm{CO} 2$ y observar el cambio de clima correspondiente ("respuesta"). La modelización del clima puede hacerse a escala global ${ }^{5}$ y regional $^{6}$.

4 La sensibilidad del clima es la temperatura de la superficie que resulta ante un aumento dado de las concentraciones de un Gl. Depende también de los mecanismos naturales de realimentación del clima.

5 La modelización global conlleva dos tipos de experimento: el de "respuesta de equilibrio" y el de ". respuesta transitoria". Para una mayor información consultar García, C (1999). "El Cambio Climático: Estado de la Cuestión y Aspectos Científicos".

6 Aunque menos avanzada se investiga mucho en la actualidad. La complicación estriba en que la resolución de los modelos no es tan refinada como para poder representar toda la geografía y los acontecimientos climáticos a una escala tan pequeña. 


\section{Gráfico 1 \\ Modelo océano-atmosférico acoplado}

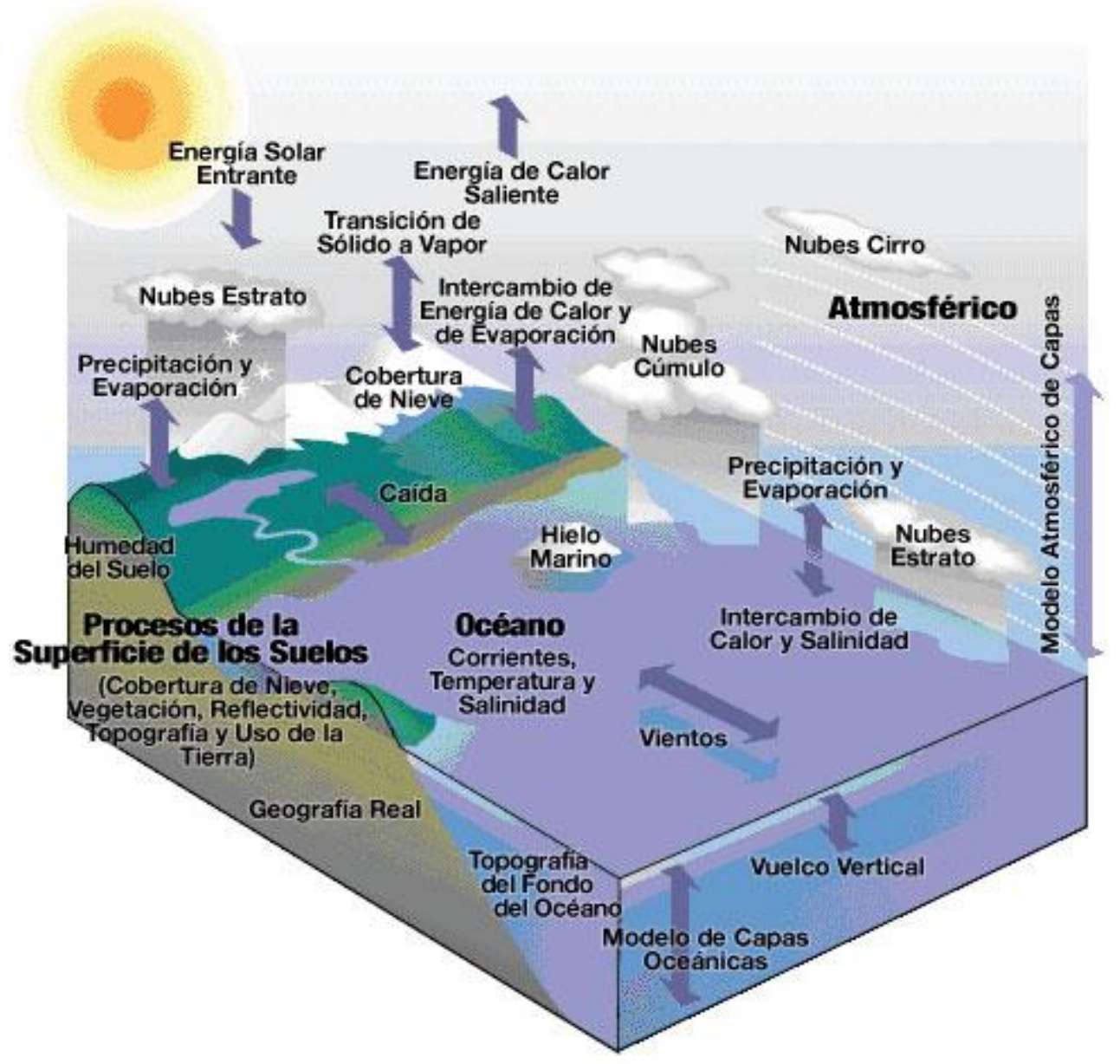

Un ejemplo reciente es el Modelo Comunitario del Sistema Climático (The Community Climate System Model) CCSM, versión 3, que corre en la supercomputadora del Centro Nacional de Investigaciones Atmosféricas, incorpora información de todos los procesos naturales que aparecen en este diagrama, el que simula el complejo sistema de clima de laTierra.

\section{LAS PRINCIPALES CAUSAS E IMPACTOS}

Una vez estudiados los principales componentes de índole científico conviene revisar aquellas actividades económicas y sectores causantes del calentamiento global. Posteriormente, ofreceremos un resumen de los impactos más importantes.

Las actividades económicas responsables del cambio climático son:

- La producción, consumo y utilización de energía. Constituyen la fuente antropogénica principal de emisiones de Gl. 
La combustión del carbón, petróleo y gas natural. Esta actividad genera alrededor de las 3/4 partes de todas las emisiones de carbono.

- La tala de bosques, la expansión de la agricultura y la destrucción de tierras húmedas. Producen el resto de las emisiones de $\mathrm{CO} 2$. Sólo la deforestación produce alrededor de 1/5 del total del CO2 expulsado y la mitad del metano liberado.

La extracción en origen y uso de los combustibles fósiles produce aproximadamente $1 / 5$ de todo el metano antropogénico, la mayor parte del $\mathrm{CO} 2$, monóxido de carbono y otros contaminantes.

- El sector industrial produce más de 1/3 de las emisiones globales procedentes de los combustibles fósiles (CF).

- Los sectores comercial y residencial son responsables del 32\% emisiones CF.

- El sector de transporte genera más del $21 \%$ emisiones y seguirá aumentando.

El siguiente cuadro muestra cual debería ser la senda de reducción de emisiones en los distintos sectores económicos para poder alcanzar el nivel de 1990 en el año 2050.

\section{Cuadro 3}

\section{Senda de reducción de emisiones de GI en la UE}

Figure 1: EU GHG emissions towards an $80 \%$ domestic reduction $(100 \%=1990)$

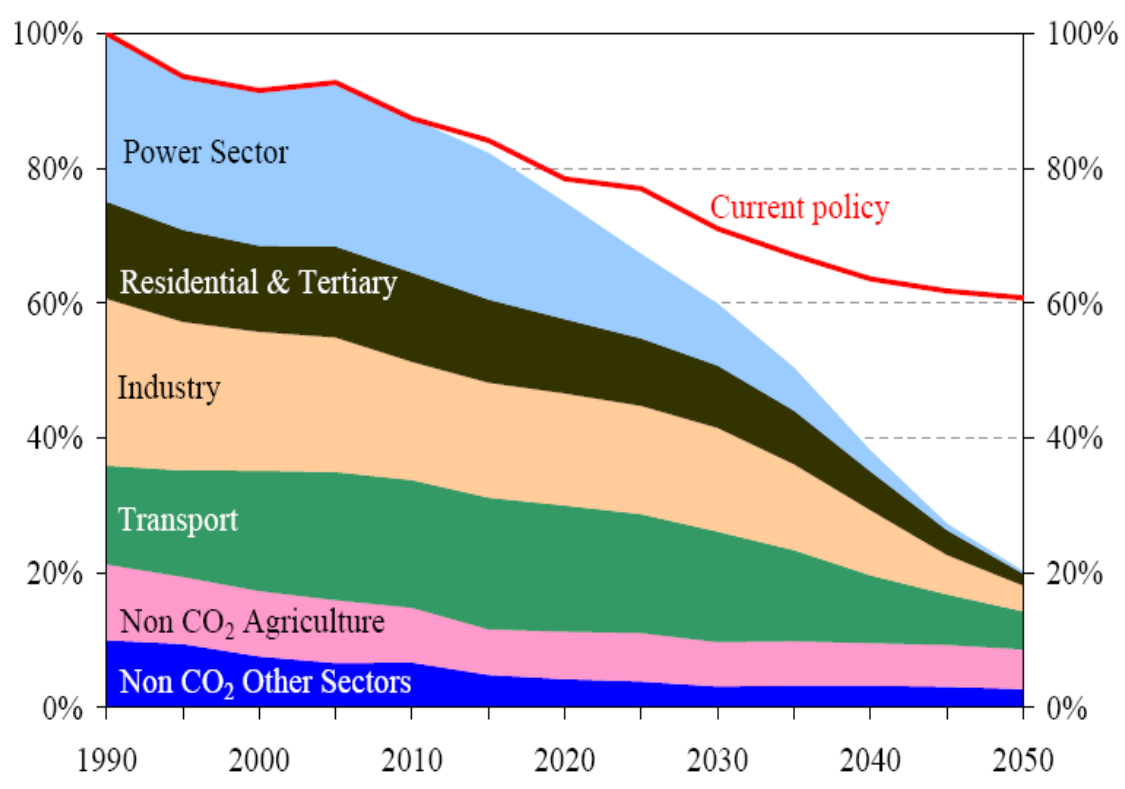

Fuente: Comisión Europea. COM (2011) 112/4 
El cuadro 3 señala a aquellos sectores que deben realizar un esfuerzo para conseguir las metas de emisiones propuestas en los últimos acuerdos internacionales (Acuerdos de Cancún). Recordemos que, según estos, los países desarrollados deberían reducir sus emisiones en un $80 \%$ (con respecto a 1990) para el año 2050.

Además, podemos apuntar algunos datos relevantes que no ofrecen mucha esperanza sobre la mejora de las emisiones anteriormente mencionadas:

- Menos de $1 / 4$ de la población mundial consume un $80 \%$ de los recursos (países desarrollados).

De estos, los Estados Unidos consumen cuatro veces más que el resto de los países industriales.

Los países en desarrollo son consumidores potenciales y, por tanto, emisores potenciales de GI.

Se espera que la demanda de petróleo aumente en los países en desarrollo debido al crecimiento de la población, urbanización, industrialización y las necesidades de transporte, a una tasa del 3,4\% anual.

Las previsiones para Europa del Este y la antigua URSS son de un aumento considerable de la demanda energía para los años venideros.

- El uso del carbón seguirá aumentando en los países que tienen grandes reservas (USA, China, antigua URSS).

- Se espera que los países de la OCDE sigan reduciendo el uso intensivo de la energía debido tanto al uso de nuevas tecnologías más eficientes como a su adaptación a la normativa internacional sobre el carbono, hecho que no les exculpa de su contribución histórica al aumento de las emisiones.

- Aun con una fuerte expansión en el uso de la energía renovable y de otras fuentes de energía bajas en carbono, es posible que los combustibles fósiles sigan representando más del $50 \%$ del suministro mundial de energía en el 2050. El carbón seguirá siendo una parte importante de la mezcla energética en todo el mundo, por lo que será necesario conseguir una vasta captura y almacenamiento de carbono para poder permitir el uso continuado de los combustibles fósiles, sin dañar la atmósfera.

En cuanto a los impactos, a continuación mostramos un cuadro con aquellos ecosistemas más vulnerables al cambio climático. Una cuestión muy importante que es necesaria tener en cuenta para las actuaciones futuras y para la aplicación inmediata de las políticas económicas preventivas es que, los cambios que sufra el medioambiente por el efecto invernadero no podrán ser modificados o controlados en el corto plazo (García, 2001). Esto se debe a las largas escalas de tiempo que tiene asociado cualquier cambio en el sistema climático. Lo que queremos decir es que, en el hipotético caso de conseguir un nivel estable de emisiones, el proceso del calentamiento global sería imparable. Esto tiene una explicación muy sencilla:

El stock de capital responsable de las emisiones tarda décadas en renovarse. 
Las concentraciones atmosféricas de gases que tienen un largo período de vida en las atmósfera requieren de largos períodos de tiempo para estabilizarse (de décadas a milenios).

Equilibrar el sistema climático dado un nivel estable de concentraciones de Gl tardaría de décadas a siglos.

Para que el nivel del mar alcanzase el equilibrio dado un clima estable sería necesarios varios siglos, y, finalmente,

Restaurar los sistemas ecológicos dañados llevaría también muchísimo tiempo (de décadas a siglos).

\section{Cuadro 4}

IMPACTOS: Ecosistemas Más Vulnerables

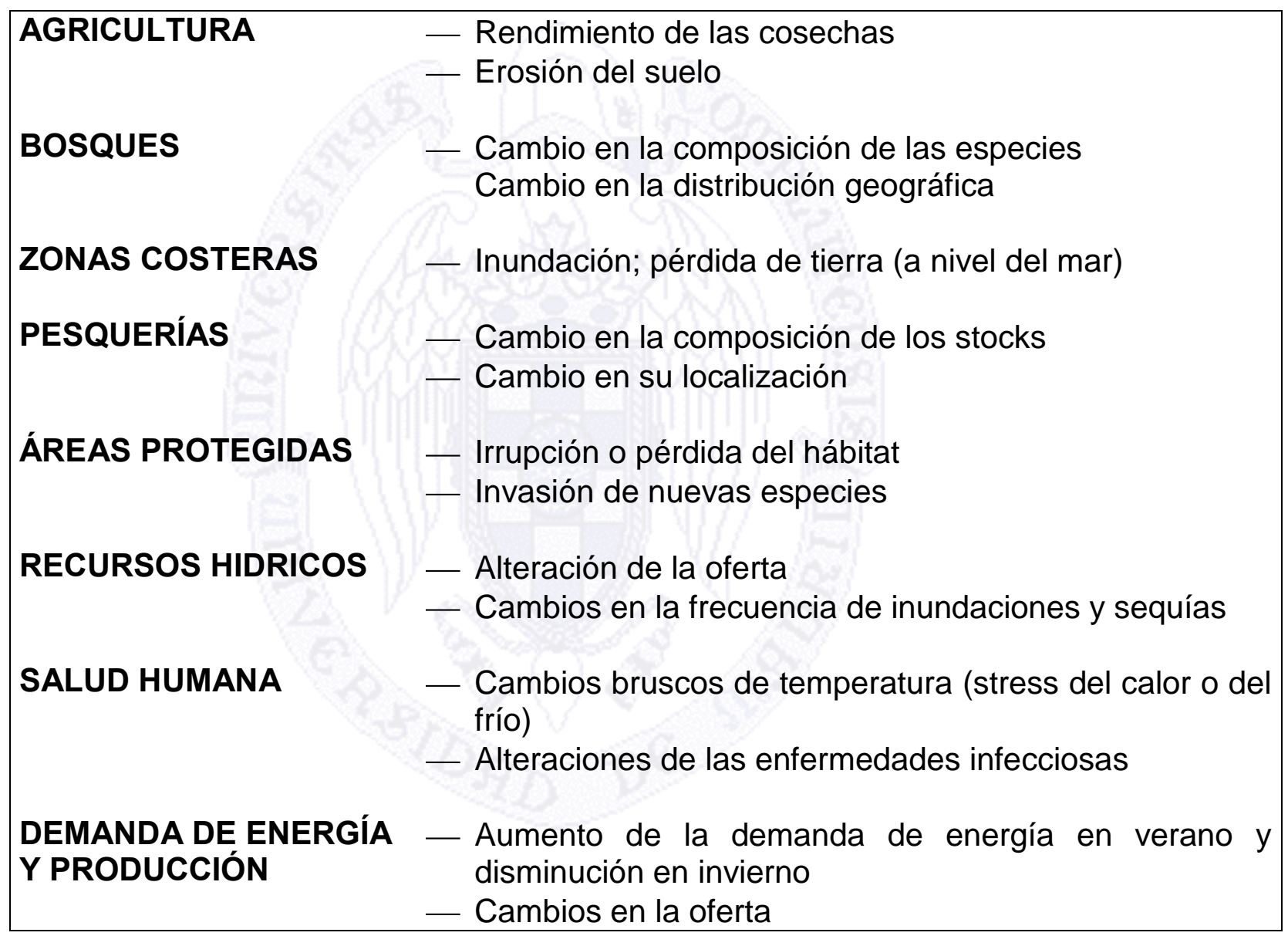

El cuadro anterior muestra algunos ejemplos de los impactos más inmediatos sobre los ecosistemas más vulnerables, pero existen otros de otra índole (económico-social) derivados de estos mismos que podrían acarrear efectos muy negativos para la sociedad. Así pues, y debido a los cambios profundos a los que nos enfrentamos, es necesaria y urgente la adopción de medidas firmes, de tipo preventivo e inmediatas, tanto a nivel nacional como internacional puesto que el cambio climático es un problema global y es imperiosa su ralentización. 


\section{LA POLITICA ECONÓMICA DE CAMBIO CLIMATICO}

\section{Las políticas económicas preventivas}

Hoy en día, disponemos de diversas políticas económicas de tipo preventivo que son capaces de reducir las emisiones de gases de efecto invernadero. La literatura existente suele definir a estas políticas como coste-eficientes ya que pueden (Clarke, R el al, 1996) lograr una reducción importante de emisiones sin tener que incurrir en un coste muy alto. Del mismo modo, estas políticas también son coste efectivas siempre que no sólo consigan recortes importantes de emisiones del gas mayormente emitido a la atmósfera, sino también de otros gases de efecto invernadero. Por ejemplo, aumentar la eficiencia energética no solo reduce las emisiones de dióxido de carbono sino también de otros gases que contribuyen altamente al calentamiento global. Pero además, una mayor eficiencia puede hacer que las industrias y los países se tornen más competitivos en los mercados internacionales. Ahora bien, las políticas económicas destinadas a mejorar la eficiencia energética, para que sean efectivas, necesitan el apoyo del público y de los grupos de interés, esto es, los gobiernos no pueden ser los únicos que tomen partido en el recorte de las emisiones, también es necesaria la colaboración de los individuos, comunidades, empresas y países. La educación y la concienciación de los ciudadanos favorecen el consumo eficiente de energía y, por tanto, la sustitución de combustibles fósiles por otros que eviten la excesiva explotación de los recursos.

Por todo lo expuesto hasta ahora y por otros motivos que abordaremos en los párrafos subsiguientes, podemos afirmar que las políticas económicas preventivas constituyen el núcleo de medidas fundamentales para evitar el avance del calentamiento global (Whaley y Wigle, 2002). La opción de adoptar una acción preventiva depende de cómo sea la relación entre los costes de reducir las emisiones de gases invernadero y los daños que estos gases pueden ocasionar si no son sometidos a ningún control. Las políticas económicas preventivas destinadas a paliar el calentamiento global tienen dos objetivos prioritarios: reducir las emisiones de los gases invernadero que hoy en día más daño están causando (CO2 y CFCs) y crear sumideros ${ }^{7}$.

Los mecanismos fundamentales para conseguir dichos objetivos son: incrementar la eficiencia energética, disminuir la producción y consumo de combustibles fósiles, sustituir los combustibles fósiles por otros menos contaminantes, fomentar el cambio tecnológico y acelerar la reforestación como sumidero primordial. Dichos mecanismos se ponen en funcionamiento a través de diversos instrumentos económicos tales como los impuestos sobre el

7 La creación de sumideros constituye una de las medidas prioritarias. La pérdida de los bosques naturales del mundo contribuye más a las emisiones globales anuales que el propio sector del transporte. Toda reducción en la despoblación forestal es un método altamente rentable de reducir las emisiones de carbono. 
carbono, la creación de mercados de derechos de emisiones, la eliminación de subsidios sobre combustibles fósiles, los programas de reforestación y de información pública sobre la eficiencia energética, etc.

Los instrumentos económicos más eficientes son aquellos que introducen diferentes incentivos para poder conseguir niveles de emisiones más reducidos, alterando, para ello, el sistema de precios. Por ello, también se les conoce como incentivos económicos o de mercado. El objetivo consiste en alterar el sistema de precios para disminuir o modificar las actividades económicas que puedan resultar nocivas para el medio natural. No obstante, todavía son las regulaciones administrativas las medidas que constituyen la mayor parte de las medidas de protección del medio ambiente. Estas no son expresamente incentivos económicos y, por tanto, no suelen alterar el sistema de precios. En general, constituyen medidas más costosas y menos eficientes que los incentivos.

Así pues, la respuesta prudente al cambio climático estaría compuesta por una combinación de políticas económicas de tipo preventivo que tuvieran la finalidad de conseguir mejoras en la eficiencia energética. Dicha prevención constituye una alternativa eficiente para adaptarse al cambio climático incurriendo en menores riesgos y propiciando el desarrollo sostenible.

Por otro lado, hay que tener en cuenta que la adopción de medidas preventivas no sólo está justificada por el riesgo que se evita, sino que también es necesario que estas tengan un punto de partida efectivo. La adopción de medidas graduales es importante, ya que de otro modo podríamos incurrir en costes prematuros (de transición o ajuste) excesivamente altos o innecesarios. Así pues, las políticas deben ser efectivas desde su puesta en marcha a la vez que adaptables a las necesidades del momento. Por ejemplo, si establecemos un impuesto sobre el carbono, este no debe partir de una tasa excesivamente alta, ya que no dejaríamos tiempo para que los mercados y los equipos se adaptaran a los nuevos cambios de los precios -o tendrían que hacerlo incurriendo en un coste excesivo-. Pero tampoco es conveniente mantener la misma tasa a largo plazo, ya que, factores como el aumento de la población y, en consecuencia, la mayor demanda de energía pueden requerir tasas impositivas mayores con el fin de evitar emisiones más cuantiosas (Barret, 1991).

También puede ocurrir que el desarrollo y puesta en marcha de las tecnologías energéticas eficientes sea más rápido de lo previsto, por lo que ello facilitaría la reducción del impuesto. La disponibilidad de nuevas tecnologías que no emitan carbono es un prerrequisito, aunque no una garantía, para reducir las emisiones de carbono a un coste razonable. El recorte de las emisiones depende también de que se reduzcan las barreras que existen en la actualidad para la difusión y transferencia de tecnología, de la movilización de recursos financieros, del apoyo a los países en desarrollo, etc. Además, la combinación óptima de políticas puede variar de un país a otro, dependiendo de factores como la estructura de los mercados de energía, de la configuración política, de la receptividad de la sociedad, etc. 
En definitiva, es necesaria que la aplicación de una política económica reductora de emisiones sea implementada de forma gradual, acorde con las necesidades del momento, que tenga en cuenta los factores de índole interno y externo del país o grupo de países donde se aplique y, que, como finalidad, su meta sea alcanzar una mayor eficiencia energética.

\section{Los costes económicos}

La argumentación anterior nos lleva al terreno de la valoración de los costes. Sobre esta cuestión existen diversas perspectivas dentro del debate del cambio climático. Por un lado, están los que afirman que todavía se sabe poco sobre el calentamiento global y que, existen tantas incertidumbres, que los costes de una política mitigadora deberían ser los únicos determinantes de las decisiones que se tomen hoy en día. En el otro extremo están los que aseguran que los costes de las políticas reductoras de emisiones no son el objetivo a tener en cuenta. Piensan que los riesgos que impone el calentamiento global son tan altos que las emisiones deben ser inmediatamente controladas a cualquier coste.

La perspectiva que se adopta en este trabajo constituye una alternativa intermedia a las dos anteriores. Creemos en la necesidad de que la aplicación de las medidas mitigadoras se haga de forma gradual, teniendo en cuenta que la ejecución de las políticas económicas de cambio climático y la evolución de ciertas variables de tipo económico y social conllevan una serie de costes. Ahora bien, particularmente importantes son los costes de reducir las emisiones de carbono, ya que pueden materializarse en pérdidas de producción o bienestar.

Por tanto, la aplicación efectiva de las políticas de cambio climático -cuyo objetivo es reducir las emisiones de gases invernadero- así como el control de las variables más influyentes en la expulsión de emisiones requieren que se incurra en un coste mínimo durante su ejecución y una estricta coordinación entre las distintas medidas para que la evolución desde el estado inicial hasta el estado final deseado sea de la forma más eficiente posible. 


\section{Gráfico 2 \\ Posibles trayectorias para la reducción de emisiones desde la perspectiva del coste}

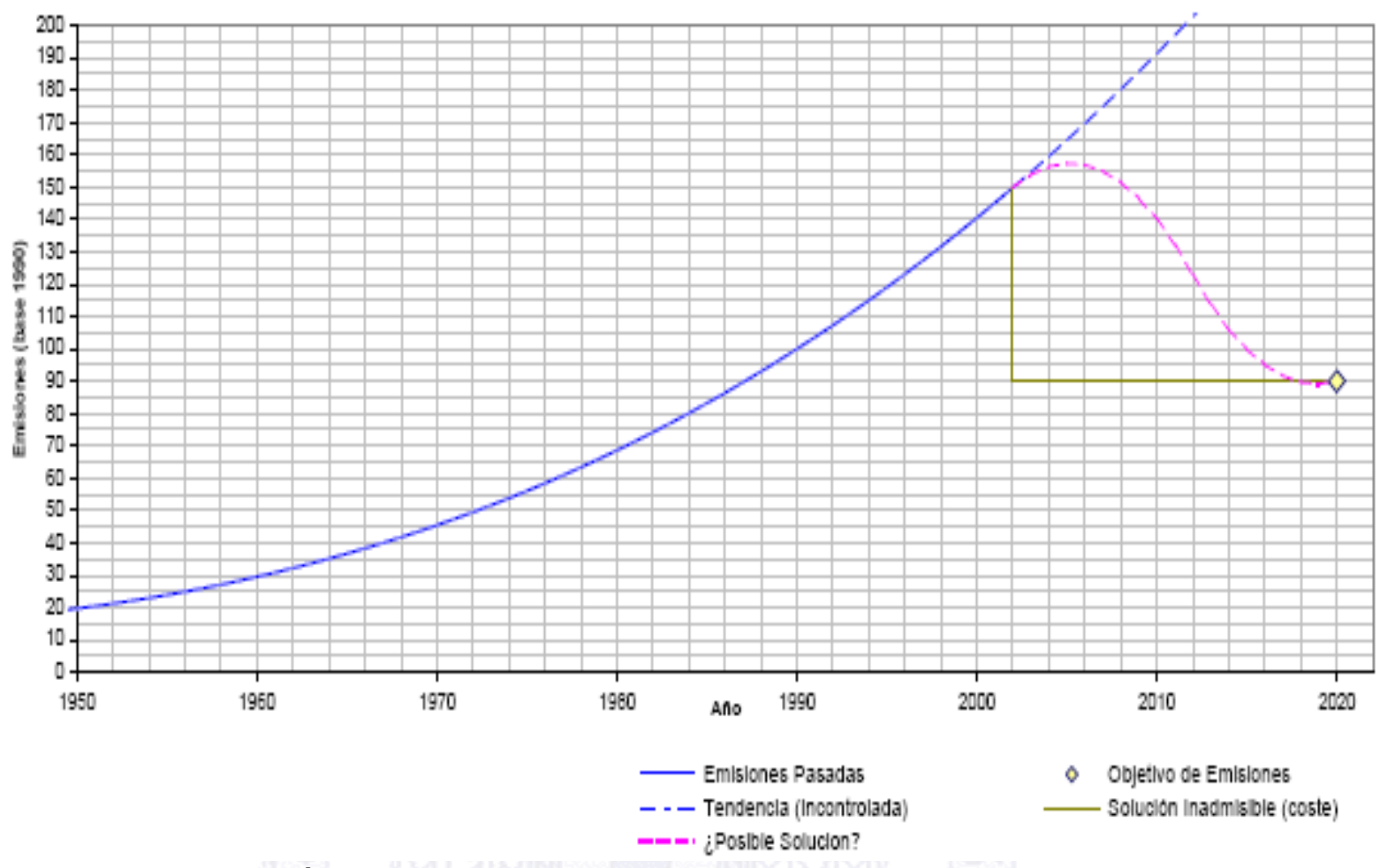

Fuente: elaboración propia

El gráfico anterior muestra una simulación sobre las posibles trayectorias que pueden seguir la reducción de las emisiones y su correspondencia con los costes que traerían consigo en los distintos casos. La cuestión primordial es que debemos aplicar instrumentos mitigadores que consigan una reducción gradual de las emisiones ya que, de lo contrario, podríamos incurrir en costes excesivos, perdiendo el objetivo de eficiencia al que hemos hecho referencia. En el gráfico, la trayectoria óptima sería la que apuntamos como "posible solución" ya que conseguiríamos reducir las emisiones (en el año 2020) a un coste mínimo o "coste-eficiencia".

En esta línea, y a la hora de calcular y valorar los costes de las políticas económicas destinadas a frenar el cambio climático, debemos considerar diversas variables. Entre las más importantes se encuentran las metas y calendarios de emisiones determinados internacionalmente, la tendencia de la población y de la economía - las expectativas son de crecimiento y con este una mayor demanda energética-, el desarrollo de nuevas tecnologías -cuanto más alta sea su disponibilidad y su tasa de incorporación menores tasas impositivas sobre el carbono serán necesarias lo cual reducirá los costes-, la tasa de reposición del capital referida al período de vida natural de los equipos en funcionamiento - cambios abruptos en el stock de capital existente pueden acarrear grandes costes si este no ha sido amortizado-, la tasa de descuento que se utilice para calcular el valor actual de la corriente de beneficios ambientales futuros, las posibles acciones que adopten los consumidores y las 
industrias en respuesta a las políticas adoptadas, al consumo de combustibles fósiles, al ritmo de avance del cambio climático, etc.

Las estimaciones sobre la cuantía de los costes de reducir las emisiones de dióxido de carbono varían de unos estudios a otros. Algunos analistas piensan que estos costes serían negativos porque las emisiones podrían eliminarse simplemente acabando con las distorsiones que tienen los mercados de energía (Clarke et al, 1996). Otros creen que si fuera posible reducir el consumo de energía a un coste negativo ya se habría hecho hace tiempo. Existen también distintos puntos de vista respecto a la evolución de otras variables: con qué rapidez aumentarán las emisiones en ausencia de políticas de cambio climático, qué mejoras de eficiencia energética pueden darse independientemente de los cambios en los precios, con qué facilidad podrán sustituirse los combustibles fósiles por otros menos contaminantes y por otras fuentes de energía y la disponibilidad y coste de nuevas tecnologías energéticas que no emiten CO2. En definitiva, y dado el rango tan amplio de incertidumbres que rodean a la evolución de las variables y a los modelos económicos que existen en este ámbito (Kesicki, 2010), no es de extrañar que existan puntos de vista diversos acerca de los costes que resultarán del recorte de las emisiones de CO2.

De acuerdo con estas consideraciones, parece evidente que una política destinada a reducir las emisiones debería lograr su objetivo con el mínimo coste posible. Como decíamos anteriormente, para que una política reductora de emisiones sea coste-efectiva, esta debe cubrir un rango muy amplio, esto es, no sólo debe conseguir recortes en las emisiones de CO2 sino también en las emisiones de otros gases invernadero. Además, la reducción de cada gas individual debería lograrse al menor coste posible. Por tanto, cualquiera que sea el tipo de política económica preventiva que pongamos en marcha esta debe ser coste-eficiente. De acuerdo con esto, los esfuerzos modestos que se lleven a cabo con el fin de reducir las emisiones de gases invernadero están económicamente justificados.

El análisis económico realizado por diversos autores a través de distintos modelos -unos utilizando el método coste-beneficio, otros calculando metas y fechas de estabilización de las emisiones y observando cuál será la pérdida de bienestar a través de la pérdida de producto nacional observada ${ }^{8}$, otros calculando los costes de la aplicación de algún instrumento económico como el impuesto sobre el carbono, etc.- sugiere que pequeñas reducciones de las emisiones y pequeñas mejoras de los sumideros pueden conseguirse a un coste nulo o muy reducido. No obstante, a medida que aumentan los recortes de las emisiones también pueden hacerlo los costes, a no ser que se desarrollen simultáneamente tecnologías más eficientes.

Hasta el momento, dado el alto grado de incertidumbre y la relativa expansión de estas tecnologías parece que las pequeñas reducciones de emisiones y de aumento de los sumideros están ampliamente justificadas. Ahora bien, si

8 Según concluye el Informe Stern, el coste anual de la estabilización entre 500 y 550 ppm de $\mathrm{CO}_{2 \mathrm{e}}$ ascendería, aproximadamente, al $1 \%$ del PIB global. 
queremos que esos costes sean cada vez menores debemos aplicar instrumentos económicamente eficientes y llevar a cabo una seria coordinación internacional de los mismos. Las políticas económicas preventivas deben complementarse con una mayor investigación sobre nuevas tecnologías y fuentes de energía alternativas que ayuden a reducir los costes y a reducir el avance del cambio climático en el largo plazo. Además, una vez que dichas tecnologías se vayan adaptando con eficiencia a los sistemas productivos estaremos en disposición de ir prescindiendo progresivamente de la utilización de los instrumentos económicos. Si esta trayectoria se va cumpliendo, en el largo plazo, los costes de reducir las emisiones serían mínimos.

\section{LOS IMPUESTOS SOBRE EL CARBONO Y LOS PERMISOS DE EMISIONES}

Entre los instrumentos económicos más importantes que pueden emplearse para frenar los impactos que padece el medio natural y, en particular, el cambio climático, se encuentran dos bien conocidos: los impuestos sobre el carbono y los permisos de emisiones. Puesto que en trabajos anteriores (García, 2008, 2009 y 2010) ya hemos realizado un análisis comparativo entre los mismos no vamos a volver a hacerlo, pero si especificar cuales son los criterios bajo los cuales debe hacerse una elección entre ambos. Los criterios son puramente económicos y resaltan la eficiencia de los instrumentos que son objeto de análisis. Los más importantes son: la eficiencia estática y la eficiencia dinámica.

El primero valora el coste de lograr una reducción de emisiones de carbono determinada ante la aplicación de un instrumento económico específico. Cuanto más bajo sea el coste, más atractivo será el instrumento. Además, es importante utilizar el supuesto de "existencia de información" acerca del instrumento que se estudia, en el caso de que se conozcan los costes que este produce. No obstante, el caso más habitual es desconocer estos costes, por lo que se procederá a hacer una nueva valoración bajo el supuesto de "no existencia de información".

El segundo criterio, eficiencia dinámica, explica la adecuación que puede tener un instrumento económico de este tipo para resolver situaciones no previstas y para crear incentivos que conduzcan al desarrollo de nuevas tecnologías capaces de resolver los problemas ambientales.

Como decíamos más arriba, la cuestión de la información es crucial en este tipo de análisis. Con el fin de poder explotar diferentes instrumentos de política medioambiental, el planificador o técnico necesita conocer los canales de información para poder aplicarlos. Por tanto, cuanto mayor sea la disponibilidad de la información, por ejemplo, sobre el coste de los instrumentos, mayor atractivo tendrá el instrumento (Dower et al, 1992).

Cuando hablamos del coste de los instrumentos económicos solemos referirnos al coste económico medido en términos de pérdida de producción o bienestar producidos por las restricciones que estos instrumentos conllevan. De otra manera sería imposible llevar a cabo una reducción de emisiones. Pero 
además, existen otro tipo de costes que son los que genera la propia gestión y control del instrumento. Cada instrumento económico requiere un control y un seguimiento diferente, ya que para que cumplan bien su cometido tienen que estar bien diseñados y gestionados. Por todo esto, $y$, debido a que el control es costoso ( $\mathrm{y}$, a veces imposible) este es un aspecto a tener en cuenta para elegir entre un instrumento $u$ otro.

Existe un alto nivel de coincidencia y abundante evidencia de que los gobiernos disponen de un amplio abanico de políticas e instrumentos de alcance nacional para incentivar la adopción de medidas preventivas. Su aplicabilidad dependerá de las circunstancias en el país y del grado de conocimiento de sus interacciones, pero la experiencia práctica adquirida en varios países y sectores indica que habrá ventajas y desventajas sea cual sea el instrumento.

\section{EL INSTRUMENTO MÁS ADECUADO}

En el epígrafe anterior hemos justificado el uso de instrumentos económicos en las políticas ambientales puesto que permiten conseguir el objetivo ambiental a mínimo coste (eficiencia estática) e introducen incentivos para una mejora ambiental continua (eficiencia dinámica). Teniendo en cuenta que esto es cierto para cualquier problema ambiental en el que exista un gran número de contaminadores de distinta índole y procedencia, en el caso del cambio climático es todavía más importante. Esto es debido, en primer lugar, a que hay muchos contaminadores heterogéneos (prácticamente todos los agentes económicos contaminan), procedentes de distintos sectores económicos que generan emisiones dispares, muchas relacionadas con la obsolescencia tecnológica. En segundo lugar, porque los costes asociados a la reducción de emisiones son potencialmente tan elevados que es esencial intentar conseguir las ganancias de eficiencia estática y dinámica.

El problema del coste ha sido y sigue siendo una de las cuestiones cruciales a la hora de utilizar los instrumentos económicos en el ámbito del cambio climático. No deja de ser lógico que los economistas tratemos de encontrar alternativas eficientes que no sólo prevengan y actúen sobre el control de las emisiones, sino que además estos controles no resulten excesivamente caros. Es por ello que el objetivo primordial de cualquier política destinada a paliar los efectos nocivos de la contaminación ambiental (en concreto la atmosférica) es que ésta sea coste-eficiente, esto es, que pueda obtenerse la reducción máxima de emisiones para un nivel dado de gasto.

Pero hay más cuestiones a tener en cuenta y es que uno de los dilemas políticos que siguen siendo centro de atención en el debate del cambio climático gira en torno a si deberían o no adoptarse medidas en el corto plazo para prevenirlo. Ser rápidos y exigentes a la hora de aplicar medidas preventivas puede suponer encarecer los costes de las mismas, de ahí que sea importante considerar todas variables. Por ejemplo, decidir sobre si es necesaria la acción preventiva depende de cómo sea la relación entre los costes de evitar las emisiones de gases invernadero y los daños que estos gases pueden ocasionar si continúan sin ser sometidos a ningún control. 
En general, los economistas tendemos a afirmar que una combinación de políticas suele ser la mejor opción, ya que la utilización de un instrumento u otro va a depender de diversos factores en cada momento. En concreto, y tras haber comparado los permisos de emisiones con los impuestos sobre el carbono en diferentes contextos podemos concluir que:

- En el corto plazo, una cuestión primordial para poder comparar impuestos sobre el carbono y permisos de emisiones desde el punto de vista de la eficiencia es la información.

- Si los agentes económicos tienen información sobre el coste del instrumento destinado a reducir las emisiones y sobre los costes sociales que estas generan (daños ambientales), entonces ambos instrumentos podrían lograr la misma reducción de la contaminación y al mismo coste (el mercado, al tener información sobre los costes, ofrecerá un precio uniforme). Tanto los costes de los instrumentos preventivos como los daños que producen las emisiones pueden representarse de forma analítica. Normalmente se representan, gráficamente, las curvas de coste marginal y las curvas de daño marginal respecto a distintos niveles de emisiones (eje de accisas).

- En cambio, cuando la información no es perfecta (caso habitual) los agentes económicos desconocen los costes marginales de las distintas fuentes de contaminación. Aquí, no esperamos que el mercado ofrezca un precio uniforme. En este caso, no ofrece igual resultado gravar las emisiones con un impuesto que establecer un sistema de permisos. Dicha elección dependerá, fundamentalmente, de las elasticidades de la curva de coste marginal de reducir las emisiones (MC) y de la curva de daño marginal (MD). En general:

- En aquellas situaciones en las que un pequeño aumento de las emisiones puede ocasionar daños muy serios en el medioambiente, deberíamos optar por el sistema de permisos (casos en los que existen razones para pensar que MD tiene mucha pendiente, es muy sensible a las emisiones, mientras que $\mathrm{MC}$ es muy plana, el coste es poco sensible a las emisiones)

- Si el daño ambiental no es tan sensible a las emisiones anuales si no a la concentración de estas, entonces será preferible el impuesto (cuando el daño ambiental ha sido causado por las emisiones acumuladas). 


\section{Gráfico 3}

Los costes dependen de las elasticidades de las curvas

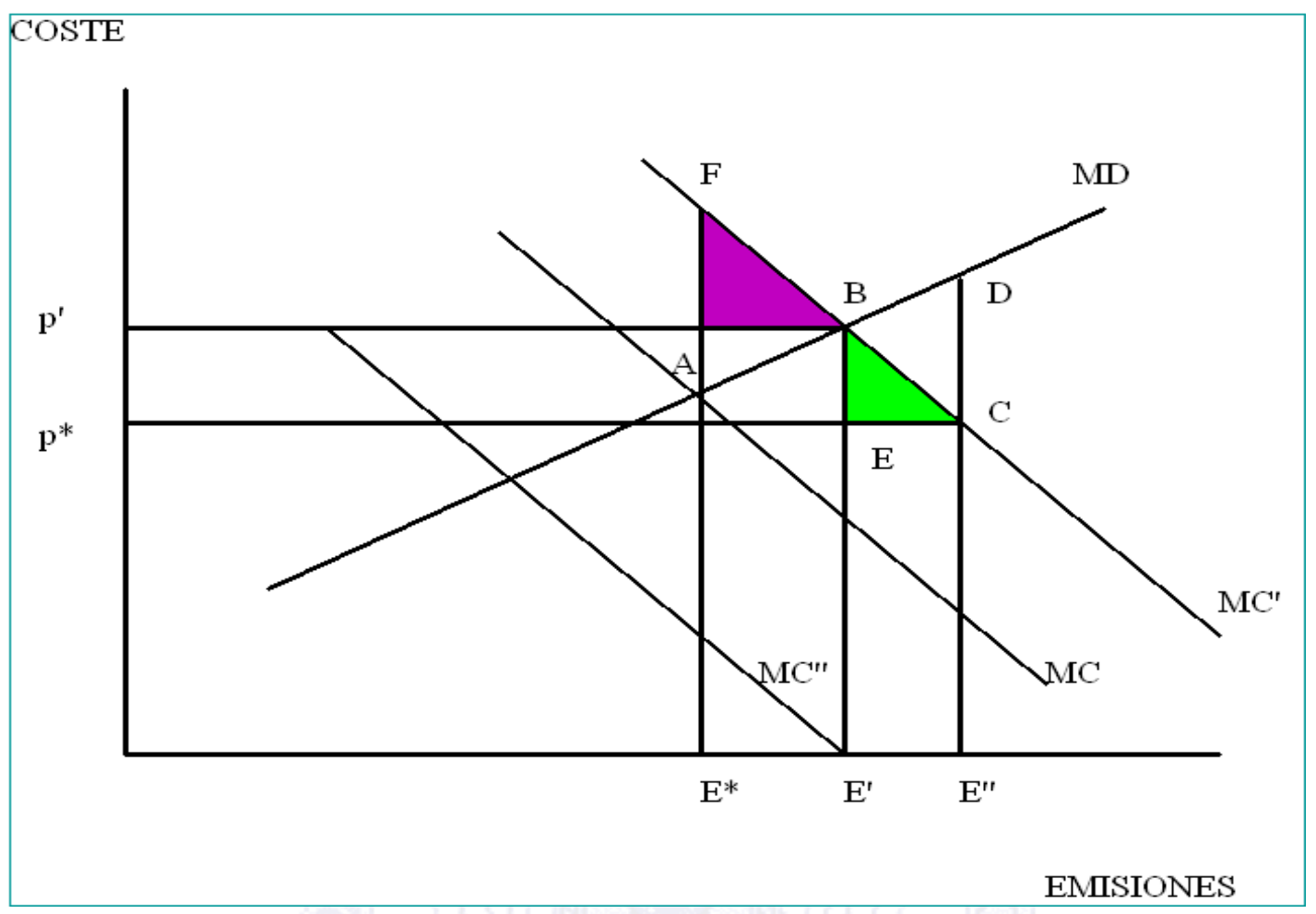

Fuente: Elaboración propia.

En el gráfico podemos ver cómo el tamaño de las áreas (sombreadas) que representan los costes netos de los instrumentos utilizados dependen de las elasticidades de las curvas MC y MD.

A largo plazo, los aspectos más importantes a la hora de elegir entre la política más adecuada son los incentivos para desarrollar nuevas y más eficientes tecnologías y el ahorro de costes que éstas generan. Por lo general, un impuesto sobre las emisiones ofrece incentivos más fuertes para desarrollar y aplicar nuevas y más limpias tecnologías que una política basada en el control cuantitativo de las mismas. Además, el impuesto es capaz de conseguir un recorte neto de las emisiones de carbono, ya que las empresas, con el fin de reducir la cuantía del impuesto, tendrán un incentivo adicional para reducir sus emisiones.

Por su parte el sistema de permisos de emisiones ofrece un resultado que depende de la asignación inicial de los permisos (que tiene consecuencias en cuanto a su distribución) y de las variaciones del precio (los permisos establecen un precio por unidad o tonelada de carbono), (Paltsev, el al, 2005). Esto es relevante ya que la fluctuación del precio del carbono hace difícil 
estimar el coste total que conllevarían los permisos de emisión ${ }^{9}$. En general, los permisos comercializables generan menores incentivos para el desarrollo tecnológico que los impuestos, pero mayores que los sistemas de regulación pura $^{10}$.

No queremos terminar este trabajo sin hacer alusión a otros instrumentos de carácter preventivo. Los incentivos financieros (subvenciones y créditos fiscales) son medios frecuentemente utilizados por los gobiernos para estimular el desarrollo y difusión de nuevas tecnologías. Aunque su coste económico suele ser más alto que el de los instrumentos anteriormente mencionados, son a menudo decisivos para superar diversas barreras. Los acuerdos voluntarios entre la industria y los gobiernos son políticamente atractivos y han desempeñado un papel decisivo en la evolución de numerosas políticas nacionales. No obstante, la mayoría de los acuerdos no han conseguido reducciones importantes de las emisiones por encima de los valores habituales. Los instrumentos de información (por ejemplo, las campañas de sensibilización) pueden afectar positivamente a la calidad del medio ambiente, ya que su misión es concienciar de los riesgos ambientales a los que nos enfrentamos y de cómo prevenirlos. Esto, posiblemente, contribuye a cambios de comportamiento entre la ciudadanía. Sin embargo, no se ha cuantificado todavía su impacto sobre las emisiones. La investigación, el desarrollo y la demostración $(I+D+D)$ pueden estimular los avances tecnológicos, reducir costes y favorecer el avance hacia la estabilización de las emisiones. Ciertas corporaciones, autoridades locales y regionales, ONG y asociaciones civiles están adoptando acciones voluntarias de muy diversa índole. Estas acciones podrían limitar las emisiones de GI, estimular políticas innovadoras y alentar la implantación de nuevas tecnologías. Por sí solas, suelen tener un efecto limitado sobre las emisiones a nivel nacional o regional.

Por último, no hay que olvidar que las políticas de cambio climático vinculadas a la eficiencia energética y a la energía renovable suelen ser económicamente beneficiosas, mejoran la seguridad energética y reducen las emisiones locales. La disminución de las pérdidas de hábitat natural y de deforestación puede ser muy beneficiosa para la conservación de la biodiversidad, del suelo y del agua, y puede conseguirse en términos social y económicamente sostenibles.

\section{CONCLUSIONES}

Este trabajo ha revisado una amplia gama de datos sobre las repercusiones del cambio climático y sobre sus costes económicos. Teniendo todo ello en cuenta,

9 Una señal de precios de carbono eficaz podría conseguir un importante potencial de mitigación en todos los sectores. Estudios de modelización indican que un aumento de los precios por carbono mundiales hasta los USD20-80/tCO2-eq de aquí a 2030 sería coherente con un nivel de estabilización en torno a 550 ppm de CO2-eq de aquí a 2100 (IPCC, 2007b).

10 Las reglamentaciones y normas suelen aportar un cierto grado de certidumbre acerca de los niveles de emisión. Podrían ser preferibles a otros instrumentos cuando la información u otros obstáculos impiden a productores y consumidores responder a las señales de precios. Sin embargo, no traen consigo necesariamente innovaciones o tecnologías más avanzadas. 
la evidencia recogida nos lleva a una clara conclusión: los beneficios de la adopción de medidas inmediatas y firmes superará con creces los costes económicos de la pasividad.

El cambio climático incidirá sobre los elementos básicos de la vida humana en distintas partes del mundo: acceso a suministro de agua, producción de alimentos, salud y medio ambiente. A medida que se va produciendo el calentamiento del planeta, millones de personas podrían padecer hambre, escasez de agua e inundaciones costeras.

La inversión realizada en las próximas décadas tendrá un profundo impacto sobre el clima durante el siglo actual y el próximo. Además, nuestra falta de determinación para actuar de forma inmediata podría producir una importante perturbación de las actividades económicas y sociales. En consecuencia, se requiere la adopción de medidas preventivas urgentes a nivel internacional, puesto que el cambio climático es un problema actual y global.

Si bien todos los países se verán afectados, aquéllos que sufrirán antes y más intensamente serán los países y poblaciones más pobres, a pesar de que son los que menos han contribuido a las causas del cambio climático. No obstante, el coste de las condiciones meteorológicas extremas, con inclusión de inundaciones, sequías y tormentas, está aumentando ya, aun en los países más ricos.

El coste de la estabilización del clima es significativo pero viable. En última instancia, la estabilización de la situación a cualquier nivel requerirá que las emisiones anuales se reduzcan en más del $80 \%$ de su nivel actual.

Si bien se trata, sin duda, de un serio reto, la aplicación de medidas económicas sostenidas a largo plazo podrían lograrlo con un coste bajo, en comparación con los riesgos resultantes de la inacción. Según estudios recientes, la adopción de medidas inmediatas podría suponer un coste anual de, aproximadamente, el $1 \%$ del PIB global (para la estabilización entre 500 y 550ppm de $\mathrm{CO}_{2 \mathrm{eq}}$ ).

Dichos costes serían aún menores si se produjeran importantes mejoras en la eficiencia o si se midieran grandes beneficios colaterales resultantes de la reducción de emisiones de Gl, tales como la reducción en la contaminación del aire. Los costes serán mayores si la innovación en tecnologías bajas en carbono es más lenta de lo esperado o si las autoridades responsables por la política a seguir no aprovechan adecuadamente instrumentos económicos que hagan posible la reducción de las emisiones donde y cuando resulte menos costoso hacerlo.

El mundo no tiene que elegir entre evitar el cambio climático y promover el crecimiento y el desarrollo. Los cambios introducidos en las tecnologías energéticas y en la estructura de las economías han creado oportunidades para separar el desarrollo de las emisiones de gases de efecto invernadero, pudiendo afirmarse que el crecimiento económico se verá negativamente afectado si se ignora el cambio climático. 
Por último, es preciso tener en cuenta que, el cambio climático constituye uno de los mayores fracasos atribuibles al mercado, fracaso que entra en interacción con otras imperfecciones del mercado. Toda respuesta global eficaz requerirá, al menos, tres elementos de política económica: el precio del carbono, aplicado por medio de impuestos, comercio de emisiones o reglamentación; una política de apoyo a la innovación y a la aplicación de tecnologías bajas en carbono; y finalmente, la adopción de medidas para eliminar cualquier barrera a la eficiencia energética e informar, educar y persuadir a los individuos sobre lo que pueden hacer, a nivel individual, para responder al cambio climático. Claramente, el cambio climático exige una respuesta internacional, cimentada sobre una comprensión compartida de objetivos a largo plazo y un acuerdo sobre los marcos para la acción.

\section{BIBLIOGRAFÍA}

- BARRET, S (1991). "Global Warming: Economics of a Carbon Tax", en Pearce, $\quad$ D. et al., (1991). Blueprint 2 ( $2^{\text {a }}$ parte de Blueprint for a Green Economy, 1989). Eartscan Publications Limited, Londres, (pp. 31 51).

- CLINE, W.R. (1992). The Economics of Global Warming. Institute for International Economics. Washinton DC.

- ClARKE, R., BOERO, G., y WINTERS, L.A. (1996). "Controlling Greenhouse Gases: A Survey of Global Macroeconomic Studies". Bull. Econ. Res., Octubre, 48 (4), pp. 269-308.

- COMISIÓN EUROPEA (2011). "A Resource-efficient Europe. Flagship Initiative under the Europe 2020 Strategy". Comunicación de la Comisión Europea COM(2011) 21.

- (2011a): "A Roadmap for moving to a competitive low -carbon economy in 20150". COM(2011) 112/4.

- ERICKSON, J. (1992). Greenhouse Earth. Tomorrow's Disaster Today. Mc Graw Hill.

- GARCÍA, C. (2010). "La Evidencia del Cambio Climático. La necesidad de las Políticas Preventivas". Nómadas (25). Revista Crítica de Ciencias Sociales y Jurídicas.

- (2010). "Los costes de la política de cambio climático: una aproximación teórica". Revista Crítica de Ciencias sociales y jurídicas.

- (2009). "La Economía del Cambio climático: las políticas preventivas y sus costes". Revista CIP-ECOSOCIAL. Boletín ECOS no 9.

- (2008). "Comparación entre Impuestos sobre el Carbono y Permisos de emisiones en el Marco de la Eficiencia económica: una evaluación teórica". Anales de Economía Aplicada, $\mathrm{n}^{\circ}$ XXII.

- (2006). "El Análisis coste-beneficio y la dificultad de su aplicación al cambio climático". Revista Estudios de Economía Aplicada.

- (2001). "El cambio climático: análisis de las causas" y "El cambio climático análisis de los impactos". UEM. Ediciones.

- (1999). "El Cambio Climático: Estado de la Cuestión y Aspectos Científicos". DT 8/99. UEM-CEES Ediciones. 
- GRUBB, M (2010). "Copenhagen, back to the future?. In Climate Policy, Vol. 10, núm 2.

- IPCC (2007a). "Summary for Policymakers", en IPCC, Climate Change 2007: The Physical Science Basis: Contribution of Working Group I to the Fourth Assessment Report of thelntergovernmental Panel on Climate Change (Cambridge: Cambridge University Press, 2007).

- IPCC (2007b). "Summary for Policymakers", en IPCC, Climate Change 2007: Impacts, Adaptation and Vulnerability. Contribution of Working Group II to the Fourth Assessment Report of the Intergovernmental Panel on Climate Change, (Cambridge: Cambridge University Press, 2007).

- JORGENSON, D.W, y WILCOXEN, P.J. (1990). "The Cost of Controlling US Carbon Dioxide Emissions". Harvard University, Cambridge, MA.

- KESICKI, F (2010). "Marginal Abatement Cost Curves for Policy MakingExpert-Based vs Model-Derived Curves". Energy Institute, University College London.

- LOPEZ, LOPEZ, A (2002). "La Política Medioambiental de la Unión Europea en Materia de Cambio Climático". Revista Observatorio Medioambiental, pg 163-191, vol 5.

- NORDHAUS, W. (2002). "After Kyoto: Alternative Mechanisms to Control Global Warming”.Yale University.

- PALTSEV, S; REILLY, J.M; JACOBY, H.D (2005). "The MIT Emissions Prediction and Policy Analysis (EPPA) Model: version 4. Massachusetts Institute of Technology.

- RUIZ DE ELVIRA, A (1991)." Problema de la interacción océanoatmosférica en los modelos del clima”. Revista Física de la Tierra $n^{\circ} 3,415$ 434. Ed, Universidad Complutense de Madrid.

- STERN, N. 2006. Stern Review on the Economics of Climate Change. Disponible en www.sternreview.org.uk

- UNFCCC Press release (2010). UN Climate Change Conference in Cancun delivers balanced package of decisions, restores faith in multilateral process. Cancun, México, 11 diciembre de 2010.

- UNFCCC documentos oficiales: www.unfccc.int.

- yABAR ESTERLIN, A (2005). Presente y Futuro de la lucha contra el Cambio Climático, en LOPEZ, LOPEZ, Alejandro y BORRELL MERLIN, Ma Dolores: Medioambiente y Desarrollo Sostenible en los Países Mediterráneos de la Unión Europea. Editan Fundación Biodiversidad e Instituto Universitario de Ciencias Ambientales (UCM). Madrid.

- WHALLEY, J. y WIGLE, R. (2002). " Cutting CO2 Emissions: The Effects of Alternative Policy Approaches"en International Trade and Environment, Judith Dean (ed). Ashgate Publishers.

- WILLIAM D. COLLINS, CECILIA M. BITZ, MAURICE L. BLACKMON (2005). "The Community Climate System Model Version 3 (CCSM3)". Journal of Climate, vol, 19. 